\title{
Autonomia e trabalho intelectual na pós-graduação em Ciências Sociais
}

\author{
Autonomy and intellectual work in Social Sciences \\ graduate studies
}

\author{
João Marcelo E. Maia \\ Jimmy Medeiros** (iD
}

\begin{abstract}
RESUMO
$\mathrm{O}$ artigo discute as práticas de trabalho dos cientistas sociais brasileiros atuantes em programas de pós-graduação. A partir de diálogo com a bibliografia sobre o tema, parte-se das seguintes questões: como os professores e pesquisadores vivenciam suas práticas de trabalho, em especial, a docência, a pesquisa e a escrita? A crescente imposição de novos mecanismos burocráticos de controle e avaliação do trabalho estaria ameaçando a autonomia do fazer científico? O texto responde ao problema valendo-se dos resultados de um survey online nacional aplicado em 2018 e de um conjunto de entrevistas realizadas entre 2016 e 2018. Sustenta-se que os cientistas sociais logram produzir espaços de autonomia no seu cotidiano, mas essa negociação permanece individualizada e sem lastro em projetos institucionais ou coletivos.
\end{abstract}

Palavras-chaves: Pós-graduação, trabalho intelectual, autonomia, ciências sociais no Brasil, ensino e pesquisa.

\footnotetext{
"Fundação Getulio Vargas, Rio de Janeiro, RJ, Brasil. Doutor em Sociologia e Professor associado do CPDOC-FGV. joao.maia@fgv.br

** Fundação Getulio Vargas, Rio de Janeiro, RJ, Brasil.

Doutor em Políticas Públicas, Pesquisador do CPDOC e coordenador de Ensino de Graduação da Escola de Ciências Sociais - FGV.

jimmy.medeiros@fgv.br
} 


\begin{abstract}
The article analyses the work practices of Brazilian social scientists in graduate programs. We critically engage with the current scholarship on the subject to raise the following questions: a) how do professors and researchers experience their work practices, particularly teaching, researching and writing? B) Is the increasing imposition of new bureaucratic mechanisms of work control threatening the autonomy of scientific work? The article answers these questions by drawing from a national survey applied in 2018 and from a set of interviews conducted between 2016 and 2018. We argue that social scientists manage to produce spaces of autonomy in their daily routines, although through a highly individualized negotiation which lacks both institutional and collective arrangements.
\end{abstract}

Keywords: Graduate program, intellectual labor, autonomy, social sciences in Brazil, teaching and researching.

\title{
RESUMÉ
}

L'article discute des pratiques de travail des spécialistes des sciences sociales brésiliens travaillant dans des programmes d'études supérieures. Sur la base d'un dialogue avec la bibliographie sur le sujet, les questions suivantes se posent : comment les enseignants et les chercheurs vivent-ils leurs pratiques de travail, notamment l'enseignement, la recherche et l'écriture ? L'imposition croissante de nouveaux mécanismes bureaucratiques de contrôle et d'évaluation du travail menace-t-elle l'autonomie de la pratique scientifique ? Le texte répond au problème en utilisant les résultats d'une enquête nationale en ligne appliquée en 2018 et un ensemble d'entretiens menés entre 2016 et 2018. On soutient que les sociologues parviennent à produire des espaces d'autonomie dans leur vie quotidienne, mais cela la négociation reste individualisée et sans appui sur des projets institutionnels ou collectifs.

Mots-clés : études supérieures, travail intellectuel, autonomie, sciences sociales au Brésil, enseignement et recherche.

\section{Introdução}

A julgar pela literatura especializada, a profissão acadêmica encontrase em crise. No contexto anglo-saxão, responsável por produzir boa parte de estudos que atesta esse mal-estar, a análise de Marilyn Strathern (2000) enfatizou como a construção de indicadores supostamente objetivos para aferir o desempenho dos pesquisadores contribuiu para uma cultura de visibilidade que desconsidera quaisquer aspectos da prática científica que não possam ser adequadamente mensurados e que dependam da confiança 
entre os atores para prosperar. Mais recentemente, Jerry Muller (2018) listou uma série de efeitos negativos produzidos pela metrificação da atividade docente e científica, tais como a promoção do "curto-prazismo", o desincentivo à inovação e à experimentação e o aumento do tempo empregado nas atividades de controle e medição.

Estudos etnográficos que tomam como objeto as práticas de ensino e aprendizagem nas grandes instituições de ensino do Norte global enfatizam os efeitos negativos desses mecanismos de governança sobre a cultura profissional dos acadêmicos, que se torna progressivamente corroída pela competitividade e pela desconstrução de laços cooperativos, os quais seriam fundamentais para a criação de projetos científicos de ponta (Hyatt et al., 2015). A “aceleração temporal” é outro efeito bem conhecido dessas transformações, produzindo rotinas de trabalho cada vez mais frenéticas e afetando a distribuição fluida das atividades necessárias para a realização de um bom trabalho acadêmico (Vostal, 2015).

As transformações estruturais que produziram esse quadro foram impulsionadas tanto pela emergência do que se convencionou chamar de "capitalismo acadêmico" (Munch, 2014), como pela disseminação de práticas neoliberais de governança nas instituições de ensino e de pesquisa, com a ampliação dos mecanismos de controle sobre o trabalho intelectual e pela criação de numerosas instâncias de aferição da performance individual de cientistas e pesquisadores.

No que se refere às ciências sociais, é necessário adicionar a esse quadro geral um desconforto produzido pela própria crise de inserção desse campo no universo profissional contemporâneo. John Holmwood (2000) analisou o caso britânico e demonstrou que a sociologia se viu fortemente afetada tanto pela introdução de novas métricas para avaliação como pela própria falta de coesão disciplinar. Ao se confundir com disciplinas de pesquisa social aplicada, a sociologia teria perdido seu distinto traço crítico e abraçado sem grandes reflexões as práticas da audit culture ${ }^{1}$ que seriam antitéticas aos valores do ofício.

Recentemente, Fernanda Beigel (2014) e Leandro Rodriguez Medina (2019) analisaram as dinâmicas entre centro-periferia e seus efeitos sobre

\footnotetext{
1 Esse conceito, que poderíamos traduzir como "cultura de avaliação", refere-se à proliferação de práticas de avaliação da produção acadêmica que instituem um conjunto de métricas ou indicadores que devem ser "atingidos". Essa proliferação baseia-se numa crença na necessidade de "transparência" e "verificabilidade" dessa produção, que deve ser constantemente auditada por gestores.
} 
a conformação das estruturas de publicação e comunicação científica das ciências sociais na América Latina. Permanece, porém, o desafio de estudos empíricos sistemáticos a respeito das práticas de trabalho concretas dos cientistas sociais no Hemisfério Sul, para além das questões de publicação e circulação internacionais.

Estudos sobre as novas formas de trabalho dos cientistas sociais brasileiros ainda são relativamente raros, destacando-se a tese de doutoramento de Marina Cordeiro (2013), que analisou os novos regimes temporais dos professores de pós-graduação e a desigual distribuição do tempo entre homens e mulheres acadêmicos. Ao analisar uma amostra de professores de programas de pós-graduação em universidades federais, Cordeiro mostra como a emergência do network-time e a intensificação do uso de tecnologias digitais produziram uma extensificação da jornada de trabalho, que invade noites e finais de semana. Mais recentemente, Maia (2019) analisou as possibilidades de autonomia intelectual em contextos de imposição crescente de mecanismos de controle do trabalho acadêmico, argumentando que é possível detectar diferentes estratégias de resistência e flexibilidade, entre as quais a construção de estratégias pedagógicas que valorizam o espaço da sala de aula, o cultivo de tempos próprios para a escrita científica e a busca por momentos para reflexão intelectual em meio às pressões do trabalho cotidiano nas instituições. A despeito dessas contribuições, ainda nos ressentimos de mais estudos sobre os efeitos das novas formas de trabalho e dos mecanismos sistêmicos que organizam atualmente a cultura avaliativa na pós-graduação sobre o ofício dos cientistas sociais acadêmicos.

Neste artigo, interessa-nos especialmente entender as práticas de trabalho dos professores de programas de pós-graduação em Ciências Sociais no Brasil. As questões que nos movem são as seguintes: como os professores e pesquisadores vivenciam suas práticas de trabalho, em especial, a docência, a pesquisa e a escrita? A crescente imposição de novos mecanismos burocráticos de controle e avaliação do trabalho estaria ameaçando a autonomia do fazer científico?

Procuramos responder a essas questões lançando mão de dois conjuntos específicos de dados empíricos, compostos pelos resultados de um survey nacional aplicado em 2018 a uma amostra de professores atuantes em programas de pós-graduação e de sete entrevistas em profundidade com 
docentes em atuação em programas de pós-graduação no Rio de Janeiro, todas realizadas entre 2016 e 2018.

O artigo está dividido em três seções. Na primeira, apresentamos a construção dos instrumentos de pesquisa e o processo de coleta de dados. Em seguida, analisamos as principais dimensões da atividade dos professores de programas de pós-graduação em Ciências Sociais: (i) prática da docência; (ii) prática da escrita; (iii) prática de pesquisa. Para tanto, combinamos os dados do survey a extratos das entrevistas realizadas, que operam como forma de detalhar as experiências tais como vivenciadas pelos próprios agentes. Finalmente, refletimos sobre os resultados à luz da bibliografia pertinente ao tema.

Nossos resultados indicam que os professores logram criar estratégias para conciliar docência, escrita e pesquisa, construindo espaços de autonomia significativos. Entretanto, isso se dá em meio a severos constrangimentos sistêmicos, que condicionam uma rotina de trabalho fortemente regulada por mecanismos avaliativos, pressões institucionais e rotinas sobrecarregadas. Sustentamos a hipótese de que os cientistas sociais logram negociar espaços e tempos de autonomia ${ }^{2}$, mas tal negociação é marcadamente individual e carece de maior sustentação na vida coletiva e institucional das instituições acadêmicas.

\section{Métodos e fontes de pesquisa}

A pesquisa empírica foi realizada no âmbito do projeto Ciências sociais em tempos de crise: novas configurações do trabalho intelectual no Brasil, financiado pela Faperj por meio do edital Jovem Cientista de Nosso Estado 2015. O projeto combinou 25 entrevistas semiestruturadas com profissionais da área, pesquisa documental e um survey online de escala nacional com professores atuantes em programas de pós-graduação.

O survey foi realizado com professores vinculados aos PPG das três áreas restritas das ciências sociais (Antropologia, Ciência Política e

\footnotetext{
${ }^{2}$ Entendemos neste artigo o conceito de autonomia intelectual à luz da discussão feita por Dick Pels (2003). Esse autor argumenta que, embora a ciência seja uma atividade construída no mundo cotidiano e imbricada com agenciamentos políticos e administrativos os mais variados, é preciso entendê-la como um continuum de práticas, que abrigam desde formas de negociação política (construir um projeto, uma equipe de pesquisa, convencer financiadores) até a construção de espaços de reflexão e isolamento individual que seriam necessários para o exercício da reflexão.
} 
Sociologia). Em 2018, identificamos 101 Programas de Pós-graduação nas três áreas de avaliação das ciências sociais, distribuídas por todo o Brasil. De forma aleatória, foram selecionados de modo estratificado, 40 programas, visando garantir a representatividade proporcional dos distintos perfis. Os estratos selecionados foram: (i) as 5 regiões do país; (ii) a nota atribuída ao PPG, considerando três faixas: "nota 3", "nota 4 ou 5" e "nota 6 ou 7"; (iii) as três áreas de avaliação na Capes/CNPq: Ciência Política; Antropologia; Sociologia. A estratificação da amostra selecionada apresentava proporcionalmente as características do total de programas mapeados, sendo este um fator importante para controlar a reprodução do perfil geral dos programas pesquisados nos dados produzidos pelo survey.

A partir desses procedimentos, foram mapeados 683 professores vinculados aos 40 PPG selecionados aleatoriamente. Eles foram contatados para a pesquisa on-line, entre o dia 11 de abril e 11 de junho de 2018. Ao todo, foram obtidos 396 questionários respondidos, perfazendo 58\% da população pesquisada. Essa proporção é considerada um dado extremamente positivo, se tomarmos como referência a estimativa de taxa de resposta "na melhor das hipóteses, entre 15\% e 30\%” (Pinheiro et al., 2006), conforme apontada pela literatura para essa técnica de pesquisa.

Uma comparação dos dados de caracterização da amostra em relação aos 683 docentes mapeados sustenta a boa representatividade amostral em relação ao universo pesquisado. Por exemplo, a diferença da distribuição proporcional de entrevistados em cada região do país frente ao universo mapeado é sempre inferior a um ponto percentual. Considerando a subárea do campo das Ciências Sociais, a proporção de docentes de Ciência Política na amostra é similar ao de docentes mapeados, todavia há uma sobrerrepresentação da área de Sociologia na amostra - em cerca de quatro pontos percentuais -, em detrimento da Antropologia, na mesma proporção. Quanto à nota de avaliação do programa, docentes em PPG de alto estrato, ou seja, com notas iguais a 6 e 7, têm quatro pontos percentuais a menos na amostra se comparados à proporção deles no universo de docentes mapeados, ao passo que docentes em PPG de estrato médiobaixo (notas 4 ou menor) têm 4,8 pontos percentuais a mais na amostra. Assim, as pequenas diferenças dessas características não impactam a ponto de inviabilizar a análise. Ao contrário, permitem desenvolver análises descritivas e inferenciais com segurança e confiança. 
Já as entrevistas foram realizadas ao longo de três anos (2016-2018), com 25 profissionais da área em atuação no Rio de Janeiro e quatro distribuídos entre Minas Gerais e São Paulo. O desenho inicial previa um número significativo de entrevistados nas variadas regiões brasileiras, mas, por motivos operacionais, não foi possível atingir tal meta.

Os entrevistados foram divididos em três grupos: (i) profissionais acadêmicos (professores de IES públicas e particulares); (ii) profissionais extra-acadêmicos (cientistas sociais que trabalham em ONGs, governos, empresas etc.); (iii) professores do ensino médio. Essa divisão foi feita a partir da leitura crítica da bibliografia pertinente para o caso brasileiro, que evidencia a concentração dos cientistas sociais no ensino (médio e superior) e na pesquisa, com menor espaço para participação em atividades do setor público, consultoria e terceiro setor, embora o cenário pareça estar lentamente se alterando desde o início da década de 2010 (Schwartzman \& Castro, 1991; Braga, 2011; Torini, 2012).

Os entrevistados eram escolhidos de forma não aleatória. Após identificar as principais formas de inserção profissional dos cientistas sociais brasileiros por meio da bibliografia, procurava-se entrevistados que pudessem se encaixar na diversidade de tipos, controlando variação geracional, institucional e de gênero. Os convites foram feitos por e-mail, por meio do qual eram esclarecidos os termos éticos adotados, que incluíam: a garantia do anonimato dos entrevistados quando da divulgação de dados e resultados extraídos das conversas; a garantia de que os entrevistados poderiam cortar ou eliminar trechos da transcrição que lhes parecessem desconfortáveis; a confiabilidade na guarda dos dados.

Para este artigo, selecionamos sete entrevistados que eram professores em programas de pós-graduação, de um total de quatorze docentes de ensino superior que participaram do projeto. Essa amostra combina diferentes gerações e vinculações institucionais, com professores que são pesquisadores CNPq em programas nota 7 e docentes em atuação em programas tidos como emergentes. Essa diversidade nos pareceu fundamental para iluminar mais adequadamente os achados do survey.

A tabela 1 apresenta um resumo das características gerais dos sete entrevistados citados neste artigo: 
Tabela 1. Síntese do perfil dos participantes das entrevistas em profundidade

\begin{tabular}{|l|l|}
\hline \multicolumn{1}{|c|}{$\begin{array}{c}\text { Nome } \\
\text { fictício }\end{array}$} & \multicolumn{1}{c|}{ Perfil do(a) entrevistado(a) } \\
\hline Marta & Socióloga, professora sênior* em PPG de estrato médio-baixo do Sudeste \\
\hline Marie & Socióloga, professora sênior em PPG de estrato médio do Sudeste \\
\hline Bernardo & $\begin{array}{l}\text { Antropólogo, professor em início de carreira em PPG de alto estrato** do } \\
\text { Sudeste }\end{array}$ \\
\hline Raquel & $\begin{array}{l}\text { Antropóloga, professora em início de carreira em PPG de estrato médio do } \\
\text { Sudeste }\end{array}$ \\
\hline Laura & $\begin{array}{l}\text { Antropóloga, professora em estágio intermediário de carreira em PPG de } \\
\text { estrato médio-baixo do Sudeste }\end{array}$ \\
\hline José Carlos & Cientista político, professor sênior em PPG de estrato médio do Sudeste \\
\hline Cristina & Socióloga, professora sênior em PPG de alto estrato do Sudeste \\
\hline
\end{tabular}

Fonte: Elaboração própria.

* Para fins de análise, consideramos "Professor sênior" os profissionais com mais de 20 anos depois de doutoramento, "Professor em estágio intermediário", aqueles com 5 a 15 anos de doutoramento e "Professor em início de carreira" os docentes com até 5 anos de doutoramento.

** No que concerne à avaliação dos Programas de Pós-graduação, um "PPG de estrato alto" possui nota 6 ou 7 na Capes, ao passo que um "PPG de estrato médio" tem nota 5 e um "PPG de estrato médiobaixo" tem nota igual a 4.

\section{Práticas docentes: o artesanato da sala de aula}

Tanto nas entrevistas como no survey, interessava-nos entender diferentes aspectos da prática docente que poderiam ser afetados pelas novas dinâmicas do trabalho intelectual, tais como: a divisão entre casa e ambiente de trabalho; o tempo e a dedicação devotados a uma atividade que não é propriamente “metrificada" pela CAPES; as estratégias de preparação de aula.

No questionário, apresentávamos um conjunto de sete perguntas que buscavam mensurar informações adicionais a respeito das rotinas de preparação das aulas para a graduação. Outras sete questões eram apresentadas para conhecer os hábitos de preparação das aulas para a pós-graduação. Todas as perguntas tinham as mesmas opções de resposta (“nunca”, "algumas vezes" e "todas as vezes”), facilitando a análise comparativa entre elas.

Esse conjunto de perguntas nos auxiliou a identificar três hábitos rotineiros para a maioria dos entrevistados, dado que tiveram proporções bem elevadas de menções: o costume de sempre incluir novos textos, o de 
reler os textos mesmo que já trabalhados anteriormente, e, por fim, o de preparar notas para a aula de maneira a facilitar a condução da mesma.

É possível identificar três diferenças marcantes de hábitos de preparação de aulas entre os níveis de graduação e pós-graduação. Por exemplo, as perguntas sobre incluir novos textos nas disciplinas ministradas repetidamente, ou mesmo em reler os textos programados que já foram trabalhados em outros anos e semestres, assim como em ler comentadores dos autores tratados em sala têm proporção menor de "todas as vezes" na graduação, reforçando a ideia de que a dedicação é menor na preparação das aulas desse nível de ensino, se comparado com a dedicação destinada à pós-graduação.

Ao que tudo indica, essa diferença significativa traduz uma concepção de que as aulas na pós-graduação demandam mais trabalho e preparação dos docentes, o que não é algo óbvio. Afinal, se as discussões feitas em âmbito de programas de mestrado e doutorado implicam maior especialização e conhecimento avançado, aulas para graduação demandam muito mais investimento pedagógico, como é de conhecimento de qualquer docente do ensino médio. Seriam esses resultados indicativos de uma crença compartilhada de que a graduação é mais “fácil” para o docente? Se o survey não nos permite aferir isso de forma objetiva, os dados qualitativos oferecem melhores possibilidades.

De modo geral, a maior parte dos entrevistados tem fortes hábitos de leitura como mecanismo de preparação para as classes ministradas, mas também reconhece que as condições institucionais e a própria divisão do trabalho acadêmico não favorecem um investimento significativo. Vejamos um exemplo de trabalho pedagógico na fala do jovem professor Bernardo:

Então, num primeiro momento, eu leio o texto, leio no livro, no papel e vou sublinhando, meus textos são todos sublinhados alucinadamente, eu tenho que arranjar coisas para criar graus de hierarquia de importância. Eu anotava as coisas mais importantes na lateral do texto, hoje em dia, eu dou tracinho nas coisas mais importantes. Aí eu pegava, depois que eu terminava o texto, tudo o que eu tinha anotado na lateral, eu passava para um programa de organização de ideias, chamado MindManager, que hoje é programa bastante tosco, mas eu aprendi a mexer nele, quem usa Evernote, essas coisas, acha tosco, mas eu não consigo usar isso. Então, é um programa que você joga as frases e organiza elas em tópicos espacialmente, por isso que eu falo 
que eu gosto de pensar espacialmente. Eu vou organizando, aí mudo a ordem das coisas do texto, assim, minha aula é expositiva, mas ela não segue de forma nenhuma a sequência do texto. Depois, eu pegava isso e transformava num arquivo de Word.

Esse conjunto de mediações entre leitura, escrita e fala foi percebida também nas entrevistas com profissionais de outra filiação geracional, como no caso de Marta, professora experiente em tradicional instituição do Sudeste. Em sua entrevista, Marta discorreu longamente sobre o uso que fazia de cadernos para escrever suas aulas e ter controle sobre os autores e as teorias que seriam discutidas:

A aula para mim sempre foi, até hoje, o grande marcador da minha semana. Eu preparo todas as minhas aulas, inclusive hoje, depois de 40 anos de ofício. As minhas aulas, algumas são escritas, ainda que eu não leia, eu escrevo (...) eu tinha um caderno e hoje eu boto no computador. São aulas que eu tenho encadernadas, em cadernos, eu trabalho com cadernos, eu trabalho preparando.

Mas, a despeito desse significativo investimento intelectual, boa parte dos entrevistados também discorreu sobre a precariedade da vida institucional e seus efeitos negativos sobre o trabalho pedagógico. Podemos ver isso na fala da professora Laura, atuante em um programa emergente:

(...) Então, a gente trabalha apesar de não ter espaço, não ter sala pra botar equipamento, a gente não tem onde colocar as coisas, não tem lugar pra reunião, não tem, não tem, não tem um monte de coisa, não tem internet.

Mas, como classificar de modo mais preciso o engajamento dos docentes com o ensino? No questionário nacional, elaboramos um índice sintético para dimensionar o engajamento dos docentes pesquisados na atividade de lecionar. Esse recurso analítico tende a facilitar nossa análise com um conjunto mais amplo de informações quantitativas. Para isso, selecionamos três ${ }^{3}$ perguntas, dentre as sete possíveis, que melhor representavam esse

\footnotetext{
${ }^{3}$ As perguntas utilizadas para representar o grau de engajamento foram: (i) Eu releio todos os textos que programo, mesmo os que já trabalhei em outros anos e semestres; (ii) Eu leio comentadores dos autores tratados em sala; (iii) Eu levanto material complementar para apresentar aos estudantes, tal como vídeos, músicas, iconografias etc.
} 
tipo de comportamento, para cada nível de docência no ensino superior. Cada vez que o entrevistado marcava a categoria "todas as vezes" em cada uma das variáveis selecionadas para a construção do índice, ele obtinha um ponto. Dessa forma, a escala de engajamento tinha limites iguais a: zero, quando em nenhuma vez a opção foi selecionada; e três, para aqueles que a marcaram nas três vezes.

Os dois indicadores reforçam a ideia de maior engajamento do público pesquisado na pós-graduação, uma vez que $50 \%$ dos docentes somaram 2 ou 3 pontos no índice. Em oposição, para a graduação, o índice delimitado obteve $33 \%$ dos casos nas mesmas categorias. Em mais uma etapa de simplificação deste indicador para facilitar a sua apresentação, consideramos os valores 0 e 1 do índice como representativos de "baixo engajamento", ao passo que os valores de soma equivalentes a 2 e 3 representam "alto engajamento".

A tabela 2 sintetiza a distribuição do grau de engajamento dos entrevistados tanto para a graduação (valores na coluna), quanto para o engajamento na pós-graduação (valores na linha). A partir desta tabela podemos identificar a representatividade dos quatro grupos. O primeiro reúne $31,2 \%$ dos docentes que possuem engajamento "alto" nos dois níveis de docência. Membros desse grupo valoram de forma parecida o trabalho nos dois níveis de atuação.

O segundo grupo é composto pelo docente tido como "desengajado" ou de "engajamento baixo" em ambos os níveis de ensino, pois alcançaram apenas um ponto ou menos nos dois índices sintéticos elaborados. Esse grupo equivale a $47,1 \%$ do total de entrevistados que responderam as seis perguntas utilizadas para esta análise, constituindo-se como o grupo mais importante numericamente.

O perfil mais desviante é composto por somente 2,4\% dos docentes que apresentam baixo engajamento na docência da pós-graduação, porém alta dedicação na graduação.

O quarto grupo, com um comportamento oposto ao anterior, soma 19\% do total dos entrevistados e evidencia a maior valoração e engajamento na pósgraduação, ou seja, possui engajamento tido como "alto" na pós-graduação, ao passo que na graduação ele é atribuído como "baixo" ou "desengajado". 
Tabela 2. Distribuição do grau de engajamento na graduação e na pós-graduação

\begin{tabular}{|c|c|c|c|c|}
\hline & & \multirow{2}{*}{\multicolumn{2}{|c|}{ Engajamento na graduação }} & \multirow{3}{*}{ Total } \\
\hline & & & & \\
\hline & & Baixo & Alto & \\
\hline \multirow{2}{*}{ Engajamento na pós-graduação } & Baixo & $47,1 \%$ & $2,4 \%$ & $49,5 \%$ \\
\hline & Alto & $19,4 \%$ & $31,2 \%$ & $50,6 \%$ \\
\hline \multicolumn{2}{|l|}{ Total } & $66,5 \%$ & $33,6 \%$ & $100 \%$ \\
\hline
\end{tabular}

Fonte: Elaboração própria.

Nota: foram desconsiderados 56 casos (14,1\% da amostra), pois parte das suas informações nas quatro perguntas ou estão em branco ou são inválidas.

De uma forma geral, essa distribuição de perfis indica baixo engajamento com a atividade docente, o que nos leva a matizar os discursos captados nas entrevistas e entendê-los, talvez, como indicadores de um desejo que nem sempre consegue se rotinizar adequadamente. Em detalhes, a presença de docentes com elevado engajamento em ambos os níveis de ensino é maior em PPG da área da Sociologia (33\%) e Antropologia (34\%), se comparado à Ciência Política (22\%). Dado interessante é que a proporção desse perfil de docente é mais comum entre as mulheres (35\%) do que entre os homens $(27,5 \%)$. Contudo, docentes que têm filho(a) com até 12 anos de idade (35\%) apresentam proporção pouco acima daqueles que tem filho(a) com idade acima de 12 anos (31\%) e daqueles que não têm filhos(as) (29\%). Os docentes casados $^{4}$ têm a menor proporção de elevado engajamento no ensino (29\%), ao passo que os solteiros (33\%) divorciados (34\%) e viúvos (44\%) declararam maior envolvimento. Embora tal correlação possa parecer anedótica, ela talvez indique um dado interessante: a situação conjugal demanda trabalho, como a tese de Marina Cordeiro evidenciou (2013), e os docentes devem racionalizar suas atividades e tempos, o que pode sugerir que o ensino seja a parte mais sacrificada.

Ademais, a proporção de docentes com elevado engajamento no ensino aumenta conforme cresce a faixa etária dos docentes entrevistados, pois passa de $28 \%$ entre professores e professoras com até 45 anos de idade para $31 \%$ entre docentes com idade entre 46 e 59 anos e aumenta novamente (38\%) dentre os docentes com mais de 60 anos. Esse dado foi corroborado

\footnotetext{
${ }^{4}$ De todas as associações estabelecidas, apenas o estado civil apresentou significância estatística $(0,05)$.
} 
nas entrevistas, particularmente nas falas de Marta e Marie, que se inserem nesse grupo de alto engajamento. De outro modo, a proporção de professores e professoras com elevado engajamento em ambos os níveis de ensino não difere entre as distintas faixas de tempo de defesa do doutorado. Isto leva a crer que o engajamento é mais estático, mudando pouco ao longo do tempo transcorrido de carreira, afinal, passa de 29\%, entre os que concluíram o doutorado há até 5 anos, para 33\% entre aqueles com mais de 20 anos como doutor. Todavia, é necessária uma investigação mais detalhada para saber se o aumento do engajamento por conta da idade do docente ocorre mais pela experiência docente ou por uma questão de atividades profissionais ligadas à geração do entrevistado. Ou seja, os professores de maior idade teriam maior inclinação pelo ensino e pela orientação.

A pesquisa identificou que há uma tendência de maior engajamento no ensino conforme cresce o engajamento institucional do docente. Ou seja, quanto maior a participação nas reuniões de departamento e colegiado, assim como em comissões acadêmicas e, ao mesmo tempo, em comissões ou direções de entidades associativas da área do entrevistado (como Associação Nacional de Pós-Graduação e Pesquisa em Ciências Sociais (ANPOCS), Associação Brasileira de Antropologia (ABA), Sociedade Brasileira de Sociologia (SBS) e Associação Brasileira de Ciência Política (ABCP) etc.), maior é o engajamento nos dois níveis de ensino. Ao mesmo tempo, bolsistas de produtividade do Conselho Nacional de Desenvolvimento Científico e Tecnológico (CNPq) (34\%) ou não (30\%) têm padrão de engajamento similar.

Esses dados nos parecem contraintuitivos e permitem ponderar os achados da bibliografia internacional, que costuma enfatizar o pesado custo das demandas institucionais sobre as práticas mais "intelectuais" do trabalho acadêmico dos cientistas sociais. As entrevistas realizadas com professores mais experientes confirmam a afirmação do artesanato da aula como espaço fundamental de autonomia e criação intelectual, mesmo quando percebem os constrangimentos produzidos pelas novas dinâmicas de avaliação em vigor nos programas de pós-graduação. Vejamos a longa análise de Marta:

Porque eu vejo muito claramente o seguinte: a ideia de formação vem perdendo espaço, a ideia da docência vem perdendo espaço, você não tem onde avaliar isso, você não tem um lugar no Lattes onde o bom professor se destaque, não há uma pontuação para isso, porque não há uma avaliação do bom professor. As instituições fazem, por exemplo, a (nome da instituição da entrevistada) tem, eu acho que algumas 
instituições devem fazer, mas isso não tem um item correspondente no currículo lattes. Então, a docência deixou de ser um lugar que ocupa a sua imaginação profissional, não é isso? Então, se eu tenho hoje 30, 40 anos eu não vou gastar duas horas do meu dia preparando aula para a graduação e mais duas preparando para a pós-graduação, gastando dois dias da semana envolvida com a docência porque eu tenho que produzir ensaios e a produção de ensaios vai fazer com que eu chegue em sala de aula com o que eu tiver ou então levo o meu ensaio para discutir com eles, o que também é tão dramático quanto eu levar o que eu quiser. Porque o seu ensaio é uma coisa muito específica que você está trabalhando. Então, esse é o dilema. (...) O sociólogo docente está em franca extinção.

A incisiva fala de Marta não a desanima de investir nos seus cadernos hoje, textos em Word -, e parece indicar um processo similar de resistência dos professores, que veem no encontro presencial com os estudantes um momento-chave da vida intelectual. Vejamos, por exemplo, dados relativos ao atendimento aos alunos fora do horário de classe, uma prática que costuma ser rigidamente regulada nas universidades anglo-saxãs e europeias. No survey, questionamos os entrevistados sobre o hábito de cada um deles em oferecer um atendimento presencial aos alunos. Considerando essa dimensão, aproximadamente nove em dez participantes da pesquisa informaram atender os alunos de maneira ampla, ou seja, sempre que procurados. Do grupo restante, $7 \%$ declararam que o atendimento é realizado mediante um agendamento prévio, de maneira que essa atividade do professor universitário seja cumprida conforme a disponibilidade e a melhor adequação da sua agenda de trabalho. O grupo minoritário restante informou que raramente atende alunos, mas o questionário não entrava em detalhes sobre as possíveis razões para tal.

Consideramos esse indicador (nove entre dez) altamente expressivo da disponibilidade dos professores e uma evidência de dois fenômenos interessantes: (i) uma recusa em "burocratizar" a relação com os discentes, evitando compartimentalizá-la em horários específicos e reduzidos; (ii) uma valorização da atividade docente para além do espaço de sala de aula. Ambas as dimensões parecem indicar que os professores logram construir espaços de autonomia e criação intelectual na docência, algo confirmado pelo entrevistado José Carlos, cientista político com larga experiência em instituição pública, que assim explicou a importância da aula para a atualização intelectual dos pesquisadores. 
É comum ir para uma aula ou outra com o texto na cabeça, texto que a gente já controla muito bem ou com as consultas, anotações, mas não dá para fazer isso seguidamente, você dá uma aula assim, você dá duas aulas assim, a terceira você tem que dar um gás senão você mesmo não suporta. Então, eu procuro sempre nos cursos fazer adaptações, de modo que o curso sirva como uma espécie de pretexto ou para eu ler coisas que já não leio há muito tempo.

\section{As práticas de escrita: lutando pelo tempo do texto}

Uma seção de nosso questionário abordou as práticas de escrita acadêmica dos pesquisados, visto que essa atividade não apenas é fundamental para a divulgação dos resultados obtidos por meio de todo o esforço acadêmico, como tem sido cada vez mais avaliada como proxy da qualidade do trabalho intelectual, que deve ser medido por meio de artigos, capítulos e livros, por exemplo.

De início, os docentes foram inquiridos sobre quais produtos científicos eles preferiam escrever. Quatro itens foram apresentados para serem ordenados, segundo a preferência pessoal - artigos científicos, capítulos para coletâneas, livros monográficos e papers para congresso, além da categoria "outros". A escolha desses itens não foi acidental. Interessavanos avaliar a aderência dos professores ao modelo do artigo em periódico, cada vez mais tido como produto por excelência do trabalho acadêmico, e a possível preferência por livros e capítulos, sabidamente populares entre pesquisadores nas ciências humanas e sociais. Note-se que a pergunta era explícita - nós queríamos saber o que os respondentes preferiam escrever.

"Artigos científicos" foram mencionados por 56\% dos participantes como sendo o item preferido em sua primeira escolha. Este produto ainda foi mencionado por 31\% dos professores como sendo o item preferido em sua segunda escolha. Outro produto mencionado com percentual elevado foi “capítulos para coletânea”, sendo indicado por 23\% dos casos como a primeira escolha. Em sequência, ele foi apontado como o item de maior proporção (35\%) pelos participantes da pesquisa na segunda escolha (Gráfico 1).

A escrita de "livros monográficos", tidos como o produto mais cobiçado nas ciências humanas, foi pouco mencionada. Apenas 13\% dos professores 
apontaram o livro como o preferido em sua primeira escolha, seguido de outros 7\% que o apontaram como o segundo item preferido (Gráfico 1). Seria esse resultado explicável pelo elevado esforço para a sua publicação, se comparado aos demais produtos pesquisados? Ou uma consequência lógica do sistema de incentivos instituído pelos mecanismos de avaliação da pósgraduação da CAPES?

Gráfico 1. Produtos científicos preferenciais para a atividade de escrita (\%)

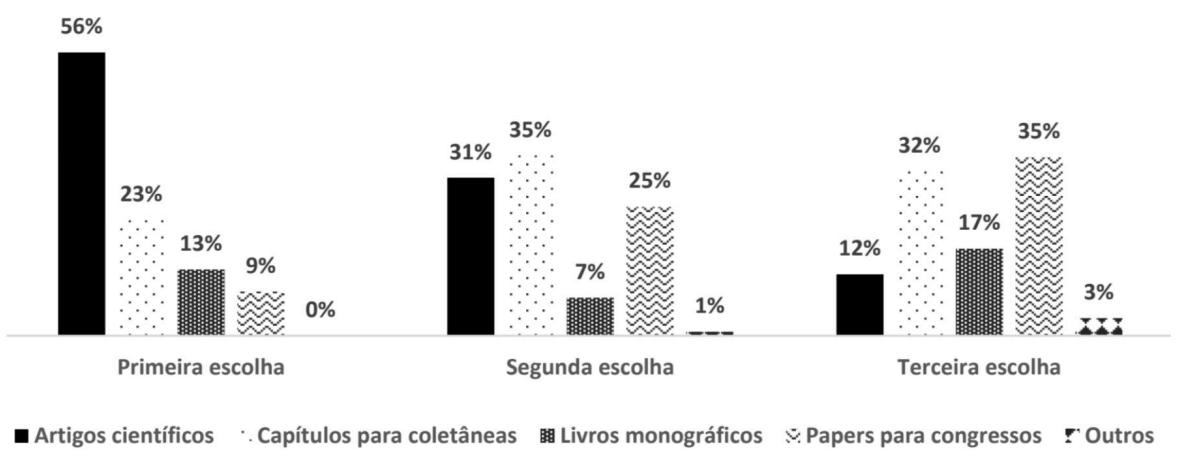

Fonte: Elaboração própria.

De todo modo, esses dados são interessantes, porque vão de encontro a um senso comum partilhado na área - de que cientistas sociais gostam de livros e que artigos são imposição da cultura disciplinar de outras áreas. Ora, o resultado encontrado pode indicar que os cientistas sociais internalizaram as práticas de trabalho demandadas pelas agências de financiamento e de avaliação da atividade intelectual, que pontuam artigos como mais valiosos. Outra hipótese seria o pouco tempo disponível para escrita de trabalhos monográficos. Esses resultados também parecem indicar que a área de Ciências Sociais está convergindo para um padrão de comunicação científica similar ao de áreas ditas "duras”, afastando-se do padrão humanista clássico, que ainda é dominante em campos como História e Filosofia. Vejamos o que as entrevistas nos permitem captar a respeito do investimento dos pesquisadores nas suas práticas de escrita. Veja-se o caso da jovem antropóloga Raquel:

Isso [a escrita] é a única coisa organizada na minha vida. Eu não consigo começar um artigo e não acabar, por exemplo. Eu tenho pastas e assim eu faço ordem, estou acabando um agora com o (anônimo), que 
é um rapaz do doutorado que está acabando, orientando da (anônimo), e tenho já um projeto na frente, tenho um projeto de livro que quando eu acabar o próximo artigo que eu quero publicar vou começar nele. Eu tenho um certo ritmo de produção de escrita, eu adoro escrever, isso para mim é uma questão importante desde o início, era uma coisa que me atraía no trabalho. Hoje a minha questão é muito mais fazer uma escrita mais ampla que eu acho que foi uma coisa que eu pensei em fazer na tese, que eu quis fazer, eu acho que funcionou, o livro tem o público relativamente amplo.

A fala de Raquel mostra a centralidade da escrita no processo de coesão do trabalho intelectual do pesquisador. Mais do que simples "demanda” a ser cumprida, escrever é possivelmente o momento que permite o encontro do cientista social com suas ideias, sua pesquisa e sua própria comunidade mais ampla. Na visão de Pels (2013), a prática da escrita permite uma operação de "atraso" fundamental para a ciência, pois retira o objeto do "buzz" do dia a dia e o insere em temporalidade mais dilatada, própria à reflexão. Não à toa, outros entrevistados manifestaram a mesma luta pela construção de espaços de autonomia referentes à escrita, em especial quando refletiram sobre a experiência de escrever a quatro mãos, algo ainda incomum em nossa área. Vejamos o que Bernardo nos diz sobre isso:

Normalmente, a gente tem uma ideia antes, conversa sobre o texto, conversa sobre a ideia, tem que se reunir algumas vezes antes, só verbal, e um dar o pontapé inicial o texto. Com o (anônimo), eu publiquei dois textos com ele, um fui eu que dei o pontapé inicial, aí mandei para ele; o outro foi ele. E aí cada vez que um lê vai revisando e fazendo comentários, trabalhando muito com os mecanismos de correção do Word, e um vai ajudando o outro mesmo. Eu tenho essa impressão de que eu funciono no diálogo. (...) todo mundo mexe em tudo. É uma conversa mesmo, acho que tanto com um quanto com o outro, a gente pressupôs uma conversa, vamos escrever como uma conversa. E aí vai comentando, às vezes não é nem para mudar o texto, mas... "Ah, isso me lembrou tal texto, me lembra tal ideia", faz piada, enfim, é até lúdico.

A fala acima é notável porque associa a escrita coletiva a um conjunto de valores e práticas associadas ao um diálogo fluido e não regrado hierarquicamente - não à toa, o entrevistado usa palavras como "conversa", "piada" e "lúdico". No caso, a escrita opera como etapa importante 
da construção de laços de sociabilidade e de ligação entre pares, algo profundamente afetado pelas dinâmicas competitivas da vida acadêmica e pelo isolamento produzido pelos mecanismos de avaliação de agências de fomento à pesquisa.

Entre entrevistados de faixa etária mais elevada, foi manifestado certo desconforto com a pressão pela publicação de artigos, como se pode ver nessa entrevista de Marie, experiente socióloga.

(...) estou atrapalhando o programa. Eu acho que eu deveria sair da pós-graduação e ficar lá só de vez em quando, eu escrevo e trabalho com os estudantes e tal. É outro ritmo, é outra coisa muito diferente. É muito diferente, em parte eu acho que era mais fácil para mim escrever antes do que agora. Tem uma sensação brutal de que eu estou escrevendo uma coisa que já está completamente sabida, que não tem nada de novo naquilo, que não tem nenhuma razão para eu estar escrevendo aquilo. Eu ontem conversava com uma amiga e ela dizia "eu não escrevo mais por isso..."

Marta, por sua vez, fez um desabafo sobre a imposição do artigo acadêmico como modelo de escrita, que estaria criando dificuldades para uma geração de pesquisadores mais acostumada ao modelo dos livros e das coletâneas. Conforme ela diz:

O problema é o seguinte: quando você participa de uma geração que está, digamos, no fim da carreira, você é solicitado a integrar coletâneas porque são pessoas que estão produzindo o que seria ou o que deveria ser uma espécie de súmula daquele tema num determinado momento. Então, os artigos que eu escrevo vão para coletâneas. Nunca eu me defronto, em primeiro lugar, com a possibilidade de enviá-los para uma revista. Isso produziu uma complicação no meu currículo. Não só na maneira como eu sou avaliada pelo meu Currículo Lattes, eu posso produzir sei lá, três ensaios, quatro ensaios por ano, mas eu não consigo sair de pesquisadora 2 porque é crucial que eu esteja escrevendo para revistas.

O survey nos permitiu identificar outros resultados mais chamativos. Por exemplo, professores da área de Ciência Política preferem escrever artigos científicos em maior proporção que os de Sociologia e Antropologia. A diferença entre eles é de aproximadamente dez pontos percentuais. Esse dado corrobora a percepção de que a área de Ciência Política é marcada por 
padrão de trabalho intelectual mais próximo do que se convencionou chamar de "hegemônico", aproximando-se do modelo anglo-saxão. É possível que tal distinção seja menos uma questão disciplinar e mais propriamente algo produzido pela pluralidade epistemológica e metodológica de nosso campo, como indica a entrevista de Cristina, socióloga com larga experiência em dados quantitativos.

Eu acho que o texto se é 8 páginas, é 8 páginas. Se é 12, se eu consegui falar em 12: “Mas tá faltando informação?”. "Não, mas tá curto”. Se eu falar em 10 beleza, melhor para quem vai ler, vai ter menos trabalho. $\mathrm{Eu}$ acho que tem uma cultura aqui no Brasil de escrever mais, tem que argumentar muito. Eu acho que eu tenho uma escola mais anglosaxônica: "Olha, a pesquisa é pra isso, eu usei esse método e cheguei a essa conclusão. Nessa discussão está fulano, ciclano e beltrano, vai lá na fonte se quiser, na teoria se diz isso, tem essa divergência, o debate é esse. Eu olhei isso e encontrei aquilo".

Além de identificar o produto preferido, a pesquisa averiguou o local preferido dos professores universitários para elaborar os artigos, textos acadêmicos e livros. A residência foi reportada por $84 \%$ dos professores como o espaço preferido, considerando a soma das opções "só escrevo em casa" e "escrevo preferencialmente em casa". O uso do escritório ou sala de trabalho é pouco mencionado como local preferido. A categoria outros reúne menções como biblioteca, cafés e indiferença, pois consegue trabalhar na escrita dos produtos acadêmicos em qualquer lugar (Gráfico 2).

Gráfico 2. Local de preferência para escrever artigos, livros e textos acadêmicos (\%)

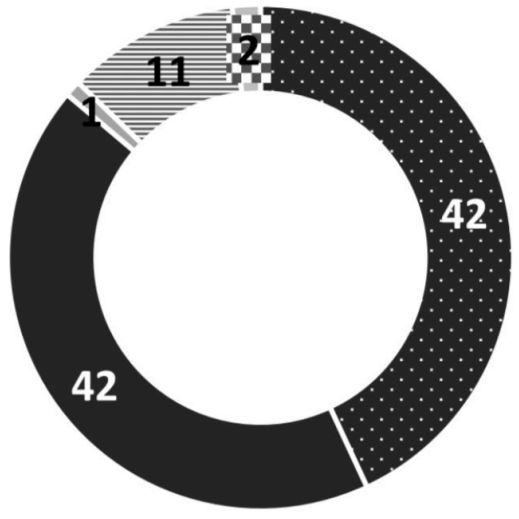

Fonte: Elaboração própria.

\section{- Só escrevo em casa}

- Escrevo preferencialmente em casa

* Só escrevo no meu escritório/sala

इ Escrevo preferencialmente em meu escritório/sala

- Outro local 
Esses dados vão ao encontro dos achados qualitativos de Maia (2019), que apontou, por meio de quatro estudos de caso, a imbricação entre o artesanato da escrita acadêmica e a valorização do espaço doméstico. Tida como atividade mais "difícil” e "sagrada” dos profissionais, ela não se adequa às demandas e aos ritmos vivenciados nas instituições de trabalho.

O último item pesquisado a respeito desse tema buscou discriminar o grau de estruturação da estratégia de escrita. O objetivo foi compreender como o docente costuma organizar de forma prática o processo de escrita. Para isso, por meio de três perguntas estimuladas, questionávamos se o pesquisado concordava ou discordava da afirmativa apresentada. De acordo com o gráfico a seguir, os entrevistados tendem a escrever seus trabalhos acadêmicos com elevado grau de planejamento. Afinal, 92\% dos entrevistados informam ter sempre "esquemas e esboços" úteis para orientar a escrita.

Em uma proporção menor, 75\% declararam concordar que sua estratégia de escrita é desenvolvida a partir de uma "boa ideia do que quer expressar". Interessante foi identificar uma diferença no comportamento desta variável intermediária do grau de estruturação segundo a vinculação à bolsa de produtividade do CNPq. Todavia, diferente do esperado, a proporção de concordância com essa afirmativa é maior entre os não bolsistas (76\%), frente à proporção declarada pelos bolsistas de produtividade (70\%). ${ }^{5}$ Isso talvez indique que a prática opere como uma espécie de ideal do trabalho intelectual, norma a que todos aspiram.

Gráfico 3. Estruturação das estratégias de escrita acadêmica (\%)

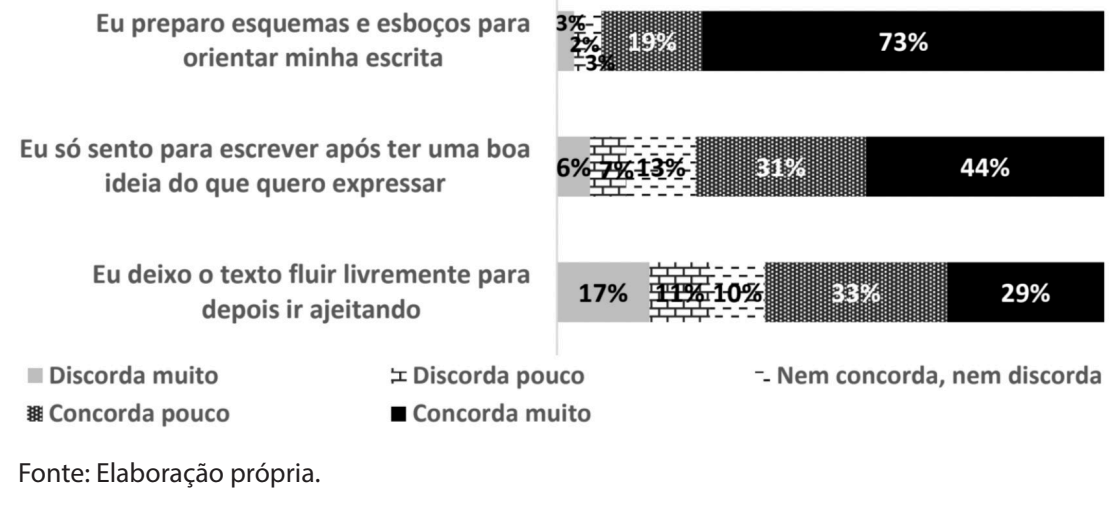

\footnotetext{
${ }^{5}$ Para esta análise, considerando o teste do qui-quadrado, há uma significância estatística ao nível de 0,05.
} 
A afirmativa com menor grau de estruturação da estratégia de escrita apresentou baixa adesão dos entrevistados. Afinal, somente $62 \%$ deles informaram que seu planejamento de escrita "flui livremente para depois ir ajeitando”. Identificamos uma diferença na concordância com esta afirmativa, segundo a área de concentração, pois docentes de PPG da Antropologia (66\%) aderem mais a essa estratégia do que docentes da Sociologia (63\%) e mais ainda que os da Ciência Política (55\%). ${ }^{6}$ Esses dados parecem indicar que a escrita antropológica tem peculiaridades derivadas do próprio modo de coleta de dados, que torna o processo de produção textual um fluxo imanente à própria reflexão sobre o campo. Não à toa, a Antropologia é a ciência social que mais avançou na reflexão sobre os pressupostos teóricoepistemológicos implicados no próprio ato da escrita.

\section{Práticas de pesquisa: criando tempos de liberdade}

A atuação em projetos de pesquisa é um dos principais aspectos do ofício dos docentes do ensino superior. Pensando nessa esfera de ação, algumas perguntas do questionário buscavam conhecer as práticas de pesquisa dos entrevistados.

Em uma das subseções, os entrevistados foram questionados a respeito do planejamento dos resultados almejados ao elaborar um projeto de pesquisa para uma agência financiadora. Conforme dados da pesquisa, 48\% dos docentes indicam que sempre preveem os resultados esperados para o projeto de pesquisa, portanto menos da metade dos participantes da pesquisa apontam um elevado grau de planejamento em suas propostas de projeto. Esse resultado não é afetado pela especialização disciplinar - os indicadores são similares para cientistas políticos, antropólogos e sociólogos.

Duas características dos docentes foram importantes para diferenciálos nesse aspecto. A primeira refere-se à vinculação ou não de bolsas de produtividade $^{7}$ do CNPq, pois o planejamento constante foi relatado por $52 \%$ dos docentes bolsistas dessa agência de fomento. Por outro lado, 42\% dos docentes sem bolsa de produtividade declaram se comportar da mesma forma, o que configura uma diferença de dez pontos percentuais.

\footnotetext{
${ }^{6}$ Para esta análise, considerando o teste do qui-quadrado, há uma significância estatística ao nível de 0,05.

${ }^{7}$ Há significância estatística na associação entre as duas variáveis ao nível de 0,05.
} 
A segunda característica identificada é o tempo de doutoramento, que pode ser adotada como uma proxy para a experiência profissional. De acordo com dados obtidos no survey, o grupo mais inexperiente, com até 5 anos com o título de doutor, é o que menos prevê os resultados a serem obtidos, pois somente 28\% declararam sempre prever. Dentre os docentes com 5 a 15 anos de doutoramento o grupo que sempre prevê o resultado cresce para 40\%. De maneira diferente, 54\% dos docentes com 15 anos ou mais de doutoramento declararam sempre antecipar os produtos almejados com suas propostas de pesquisas. Dessa forma, neste quesito, o tempo de atuação profissional é um fator positivo para a estruturação de um projeto ${ }^{8}$. Se pensarmos as variáveis "tempo de doutoramento" e "bolsista de produtividade" conjuntamente, veremos que a maior estruturação dos projetos de pesquisa é fator relacionado à socialização profissional nos rituais da vida acadêmica. Isso pode ser mais bem compreendido pela entrevista de Cristina, com longa experiência em projetos quantitativos e forte liderança institucional em sua área. Ela diz:

Eu acho que fazer pesquisa, lógico que você aprende, aprende técnicas, mas eu acho que (...) um bom pesquisador é igual pianista, você pode aprender a tocar piano, mas ser um bom pianista tem que ter alguma coisa diferente. Eu acho que tem que ter curiosidade, tem que ter uma cabeça arrumada... por exemplo, eu vou dar agora o curso de “Introdução à Metodologia das Ciências Sociais”. Eu passo o curso praticamente inteiro ensinando a fazer um projeto de pesquisa: o que é um problema de pesquisa, o que é objetivo, o que é objeto, o que é justificativa, o que é objetivo principal ou secundário, como é que você faz, se você vai montar um questionário o que dá certo e o que não dá, seja ele um quanti ou um quali, um roteiro de grupo focal.

O cientista político José Carlos, por sua vez, associa a expertise na elaboração de projetos e na gestão de pesquisas a um traço geracional - a socialização sua e de colegas de idade similar nas ONGs e em outras instâncias de produção de conhecimento fora da vida estritamente acadêmica.

Acho que a minha geração a experiência de ONGs foi muito importante para muitos de nós, muita gente legal que está aí nas universidades, são lideranças de grupos de pesquisa tiveram essa experiência em ONG. E ONG a dinâmica é muito diferente da dinâmica dos estudos de pesquisa

\footnotetext{
${ }^{8}$ Neste caso não há significância estatística na associação entre as duas variáveis. Todavia, descritivamente a relação linear é evidente e contribui em identificar um possível padrão.
} 
e, sobretudo das universidades públicas porque era pesquisa aplicada, então aquela pesquisa de resposta à demanda e tudo muito rápido, muito intenso. Então, eu acho que quem tem teve essa experiência ganhou muito em termos de traquejo na feitura de pesquisa, redação de relatório, produção de projeto de pesquisa para captação de recurso porque a gente estava sempre com a corda no pescoço, então eu acho que foi um campo e acho que ainda é, embora de forma muito diferente do que era nos anos 90, foi um campo e ainda é um campo muito importante no processo de profissionalização da minha geração que fez pós-graduação ao longo dos anos 90.

Mas, como os profissionais conseguem lidar com os ritmos e os tempos da pesquisa em meio a um ambiente institucional fortemente veloz e competitivo, que produz acúmulo de demandas e obrigações? No questionário, buscamos compreender as diferentes estratégias de pesquisa desenvolvidas pelos entrevistados após obtenção de financiamento da pesquisa. Nesse sentido, o mais comum é docente que "procura se dedicar diariamente à pesquisa, mesmo que tenha pouco tempo disponível”, que constitui 49\% dos casos. Outro grupo só se dedica à pesquisa em períodos específicos, como mencionado por 36\%, que "espera um momento mais tranquilo no semestre, em que não haja aulas ou outras atividades”; outros 3\% de entrevistados mencionaram que "só fazem pesquisa durante períodos sabáticos, férias ou pós-doutoramentos”, sendo mais restrito e pouco comum.

Essa informação permite problematizar o que a literatura internacional tem apontado, demonstrando forte resiliência dos pesquisadores brasileiros que, a despeito dos múltiplos engajamentos profissionais, procuram se manter ativos como pesquisadores. Essa busca, por vezes, permite a construção de tempos um pouco mais livres para investigação, embora as soluções sejam eminentemente individuais, demandem custosos esforços que sobrecarregam outras dimensões da vida e ainda careçam de coordenação coletiva.

Voltando aos dados do questionário, vale dizer que o perfil de docência na graduação e pós-graduação foi importante para diferenciar os entrevistados. Por exemplo, somente $22 \%$ daqueles que lecionam apenas na graduação “procuram se dedicar diariamente à pesquisa”. Essa proporção sobe para $47 \%$ dentre os docentes que lecionam na graduação e na pós-graduação. Todavia, aumenta para $75 \%$ dentre os docentes que leccionam apenas na pós-graduação e que tendem a dedicar um menor tempo em sala de aula. 
Uma estratégia detectada nas entrevistas foi a diluição das etapas de pesquisa ao longo dos dias de trabalho, algo mais factível para os que trabalham com dados quantitativos. É o caso de Cristina:

A pesquisa não tem rotina, mas ela é uma constante, então assim, ou eu estou trabalhando com dados já existentes, mas para mim isso é... porque você está rodando, você está pensando modelos, você está pensando o problema da pesquisa e como acessar àquilo. Eu adoro. Eu adoro sentar na frente do programa: "Poxa, só deu esse resultado na regressão, será que é isso?”. Você ficar ali investigando.

É claro que tal estratégia não funciona para todos os pesquisadores, já que cada área tem questões muito próprias relativas à coleta de dados - em especial, a Antropologia. Vejamos o que a jovem antropóloga Raquel nos diz:

Eu consigo ter uma questão, formar uma questão, ter uma noção do que eu preciso de dado empírico para trabalhar aquela questão e ir para campo com aquelas questões. É um campo muito mais limitado do que eu fazia antes, aquela observação, vou morar no lugar, vou ficar no bar esperando uma conversa acontecer ou então vou acompanhar um evento de tal coletivo, ou vários eventos, nada disso dá para fazer agora, não consigo ainda.

Mas é notável que, mesmo em um cenário em que não há tempo para uma pesquisa contínua, a entrevistada consegue construir estratégias que aliam pesquisa à docência, construindo tempos de liberdade que desafiam a compartimentação de práticas tão comum aos mecanismos avaliativos. Segundo ela:

Mas, o que eu fiz ano passado que foi legal e funcionou foi fazer campo com os alunos, fiz, eu fazia o meu campo, eles faziam e a gente trocava, era no mesmo lugar, eles iam para um lado e eu ia para o outro. (...)Eu fazia uma preparação para eles de paisagem, observação em sala e a gente ia para o campo, eu fazia o campo que eu queria, cada um ia para o lado e a gente se reencontrava no final e conversava, e depois na aula de novo. Então, isso funcionou bem e depois consegui completar um dia ali outro aqui indo sozinha.

Como se vê, os dados extraídos do survey e as entrevistas evidenciam diferentes aspectos relacionados à negociação da autonomia dos professores 
de PPGs de Ciências Sociais no Brasil. Para um melhor entendimento da significância sociológica desses achados, é fundamental pensá-los à luz da bibliografia sobre o tema, como fazemos na seção a seguir.

\section{Considerações finais}

Embora os resultados aqui apresentados sejam restritos ao caso brasileiro, eles nos permitem debater o diagnóstico pessimista que marca a literatura feita no Norte Global e construir um juízo mais matizado sobre o ofício dos cientistas sociais acadêmicos. A docência e o atendimento aos alunos continuam sendo atividades fundamentais para os cientistas sociais brasileiros. As entrevistas nos permitiram detectar uma constante reflexividade contida no ato de ensinar, que se articula com etapas e modos de raciocínio característicos da pesquisa. A escrita, embora transformada em uma mercadoria que circula prestígio e reconhecimento, moedas por excelência do campo científico, ainda guarda vinculação com a expressividade e com a construção intelectual autônoma dos pesquisadores, ao menos no plano normativo desses sujeitos. Finalmente, detectou-se a resiliência da pesquisa como atividade contínua dos docentes analisados, embora profundamente afetada pelas constantes "quebras" de tempo produzidas pelo acúmulo de funções e atividades institucionais. É possível, portanto, vislumbrar a construção de espaços de autonomia nessas práticas, embora com limitações. Ou seja, no lugar da oposição entre artesanato e alienação, temos um quadro pautado pelas construções de tempos e espaços de autonomia num cenário caracterizado por imperativos sistêmicos bem descritos na literatura, e que também foram verificados no caso brasileiro. Entende-se, portanto, que a autonomia não é um horizonte utópico marcado pela negação do trabalho científico profissionalizado, mas uma difícil negociação diária com os vários tempos associados aos diferentes agenciamentos da ciência.

De certo modo, esses resultados vão ao encontro do que parte da literatura que vem sendo produzida no Sul global aponta. Recentemente, Collyer et al. (2018) analisaram as práticas de trabalho de cientistas atuantes em três áreas interdisciplinares emergentes - HIV; estudos de gênero; mudanças climáticas - em três grandes países do hemisfério (Austrália, Brasil e África do Sul). Também investigaram a construção da vida institucional e científica 
nesses países e as formas de intercâmbio e trocas com os países centrais do hemisfério Norte. Seus resultados mostraram que a conhecida prática de extroversion, isto é, a adoção de padrões exógenos de validação e legitimação institucional, não anulou o potencial de construção autônoma de agendas e espaços de produção de conhecimento no Sul. Já os estudos de Leandro Rodriguez Medina (2019) e Koch e Vanderstraeten (2019) mostraram que, embora a internacionalização científica seja pautada por padrões e critérios globais que podem ser uniformizadores e restritivos, é possível detectar a formação de redes regionais de citações e práticas contra-hegemônicas de internacionalização. Nesse sentido, é possível sustentar que a literatura produzida a partir do hemisfério Sul sobre o ofício dos cientistas sociais acadêmicos pode oferecer perspectivas menos sombrias sobre os efeitos da racionalização científica e do "capitalismo acadêmico".

Uma hipótese que explique isso seria a existência de diferentes tradições intelectuais de engajamento e ciência pública nesses países, como demonstrou Wiebke Keim (2011) para o caso sul-africano, Perlatto e Maia (2012) para o caso brasileiro e Juan Pedro Blois (2015) para os casos argentino e brasileiro. Finalmente, não se deve descartar a própria configuração institucional do mundo acadêmico brasileiro, que é marcado pela estabilidade do serviço público. Essa é, certamente, uma poderosa barreira ao fenômeno da casualização e precarização que ameaçam o trabalho intelectual em parte da Europa e nos Estados Unidos.

Mas é necessário dizer que os processos de construção da autonomia analisados neste texto são eminentemente individuais. Nas entrevistas, em especial, foi patente a dificuldade de pensar o espaço coletivo como pertinente para o florescimento intelectual dos docentes. Além disso, essa busca por autonomia, por vezes, ocorre com grandes esforços pessoais que implicam custos para a vida pessoal dos docentes, em especial para a saúde mental. Esses fatos, que pretendemos discutir com mais detalhamento em um artigo próximo, nos parecem representar um grande desafio para a construção de políticas públicas que permitam conciliar as responsabilidades da ciência (impacto, relevância e alcance) com os valores democráticos que são cruciais para a produção de conhecimento. 


\section{Referências}

Beigel, Fernanda. (2014). Publishing from the periphery: structural heterogeneity and segmented circuits. The evaluation of scientific publications for tenure in Argentina's CONICET. Current Sociology, 62(5), 743-765. https://doi.org/10.1177\%2F0011392114533977

Blois, Juan Pedro. (2015). La institucionalización de la sociología en Brasil y Argentina. Formación, organización e intervención de los sociólogos. Estudios Sociológicos, 33(99), 633-658. https://doi.org/10.24201/ es.2015v33n99.1393

Braga, Eugênio C. F. (2011). Novos elementos para uma sociologia dos cientistas sociais: a situação ocupacional dos egressos. Revista Brasileira de Ciências Sociais, 26(76), 103-122. https://doi.org/10.1590/ $\underline{\text { S0102-69092011000200006 }}$

Collyer, Fran, Connell, Raewyn, Maia, João M. E., \& Morrell, Robert. (2018). Knowledge and global power: making new sciences in the South (1. ed.). Monash University Publishing.

Cordeiro, Mariana C. (2013). Você tem tempo? Uma análise sobre as vivências temporais dos acadêmicos em ciências sociais na sociedade contemporânea [Tese de Doutorado, Universidade Federal do Rio de Janeiro]. https://minerva.ufrj.br/F/?func=direct\&doc number $=000803074 \&$ local base $=$ UFR01

Holmwood,John.(2000).Europeand the “Americanization” ofBritishSocialPolicy. European Societies, 2(4), 453-482. https://doi.org/10.1080/713767001

Hyatt, Susan B., Shear, Boone W., \& Wright, Susan. (2015). Learning under neoliberalism: ethnographies of governance in higher education. Berghahn Books.

Keim, Wiebke. (2011). Counterhegemonic currents and internationalization of sociology Theoretical reflections and an empirical example. International Sociology, 26, 123-145. https://doi.org/10.1177\%2F0268580909351324

Koch, Tomás, \& Vanderstraeten, Raf. (2019). Internationalizing a national scientific community? Changes in publication and citation practices in Chile, 1976-2015. Current Sociology, 67(5), 723-741. https://doi. org/10.1177\%2F0011392118807514

Maia, João M. E. (2019). Ciências Sociais, trabalho intelectual e autonomia: quatro estudos de caso sobre nós mesmos. Dados - Revista de Ciências Sociais, 62(2), 1-33. https://doi.org/10.1590/001152582019178 
Maia, João M. E. (2015). Ciências sociais em tempos de crise: novas configurações do trabalho intelectual no Brasil [Projeto de pesquisa financiado pela Faperj por meio do edital Jovem Cientista de Nosso Estado]. Fundação de Amparo à Pesquisa do Estado do Rio de Janeiro.

Medina, Leandro R. (2019). Enacting network, crossing borders: on the internationalization of the social sciences in Mexico. Current Sociology, 67(5), 705-722. https://doi.org/10.1177\%2F0011392119833101

Muller, Jerry. (2018). The tyranny of metrics. Princeton University Press.

Munch, Richard. (2014). Academic Capitalism: universities in the global struggle for excellence. Routledge.

Pels, Dick. (2003). Unhastening science: autonomy and reflexivity in the social theory of knowledge. Liverpool University Press, 2003.

Perlatto, Fernando, \& Maia, João M E. (2012). Qual sociologia pública? Uma visão a partir da periferia. Lua Nova, (87), 83-112. https://doi.org/10.1590/ $\underline{\text { S0102-64452012000300005 }}$

Pinheiro, Roberto M., Castro, Guilherme C., Silva, Helder H., \& Nunes, José M. (2006). Comportamento do consumidor e pesquisa de mercado. Editora da FGV.

Schwartzman, Simon, \& Castro, Maria Helena M. (1991). A trajetória acadêmica e profissional dos alunos da USP [Documento de Trabalho 2]. NUPES. http://nupps.usp.br/downloads/docs/dt9102.pdf

Strathern, Marilyn. (2000). The Tyranny of Transparency. British Educational Research Journal, 26(3), 309-321. https://doi.org/10.1080/713651562

Torini, Danilo M. (2012). Formação e identidade profissional: a trajetória dos egressos de Ciências Sociais [Tese de Doutorado, Universidade de São Paulo]. https://doi.org/10.11606/D.8.2012.tde-09012013-160019

Vostal, Filip. (2015). Academic life in the fast lane: the experience of time and speed in British academy. Time $\mathcal{E}$ Society, 24(1), 71-95. https://doi. org/10.1177\%2F0961463X13517537

\section{$(\mathrm{cc}) \mathrm{Br}_{\mathrm{Br}}$}

Licenciado sob uma Licença Creative Commons Attribution 4.0 